\title{
A encruzilhada brasileira na ordem ambiental internacional das mudanças climáticas
}

\section{CAROLINA GAMBA e WAGNER COSTA RIBEIRO}

$\mathrm{E}$ M QUE PESE todas as dúvidas acerca dos assuntos concernentes às mudanças climáticas, consolida-se cada vez mais uma ordem ambiental internacional das mudanças climáticas (Ribeiro, 2001). Essa vem sendo delineada a partir da década de 1970, sobretudo desde 1992, quando foi definida a Convenção Quadro das Nações Unidas sobre Mudança do Clima (United Framework Convention on Climate Change - UNFCCC). Ainda que seja também reflexo do conhecimento científico, ela possui ritmo próprio, flutua de acordo com os interesses dos agentes que a compõem, bem como pela conjuntura de cada rodada de negociações.

Este artigo apresenta um relato sobre a Décima Oitava Conferência das Partes da Convenção-Quadro das Nações Unidas sobre Mudança do Clima (COP-18), realizada entre os dias 26 de novembro e 7 de dezembro de 2012, em Doha, no Emirado do Qatar. Nele encontram-se as principais decisões da COP-18, com destaque para as posições brasileiras na reunião. Para tal, está dividido em três partes: COP-18 - metas, discussões e resultados; as posições brasileiras e considerações finais. Ele é resultado da combinação de informações obtidas diretamente no evento com referências que discutem as negociações internacionais sobre as mudanças climáticas.

\section{COP-18 - metas, discussões e resultados}

Ao longo de duas semanas, representantes de 193 países - membros da Convenção e observadores - buscaram estabelecer um diálogo para definir o futuro das negociações sobre o sistema climático. A maior preocupação era construir uma alternativa ao desenvolvimento que não aumente as emissões de gases estufa, em especial pelo alerta da elevação das emissões desses gases a níveis preocupantes. A chamada para a reunião de Doha mantinha a polêmica que envolve as discussões da ordem ambiental internacional das mudanças climáticas desde seu início, ou seja, quem vai financiar tanto as ações de redução de gases estufa quanto as voltadas para a adaptação às consequências das alterações climáticas, em especial para os países mais pobres.

Com esse tema em destaque, registrou-se a participação de mais de cem ministros nas sessões de alto nível. Além dos delegados governamentais, tam- 
bém participaram do evento representantes empresariais, diversas organizações ambientais, mais a mídia internacional. $\mathrm{O}$ evento tinha várias metas, apresentadas a seguir.

\section{Metas}

A agenda da COP-18 tinha uma série de objetivos-chave. O mais importante era garantir a continuidade do Protocolo de Quioto. Na reunião de Durban COP-17 foi decidida a prorrogação do Protocolo de Quioto até 2017. Para a maioria das partes, seu prosseguimento serviu como alicerce para aumentar a confiança política internacional no tocante à responsabilidade dos países desenvolvidos em impulsionar as reduções de emissões de gases de efeito estufa. Além disso, significou a conservação do próprio modelo do Protocolo, em termos de sistema legal e de contabilidade e indicou um caminho para a formação de outros acordos.

O Protocolo de Quioto foi abordado em dois pontos centrais: a duração do segundo período de compromisso e conversão dos objetivos nos chamados Objetivos Quantificados de Limitação e Redução de Emissões (OQLRE); e a formulação legal da emenda do Protocolo, que também incluía como transferir os créditos de emissões não esgotados das economias em transição para essa nova fase.

Um dos objetivos da COP-18 era planificar o trabalho da Plataforma de Durban, para que se cumprissem as tarefas e os prazos acordados durante a COP-17 de modo a considerar as circunstâncias específicas de cada país em um acordo "eficaz, ambicioso e justo", como foi amplamente divulgado em Durban. Ressalta-se que na COP-17 os países-membro decidiram por um acordo universal, que vai englobar todos os países a partir de 2020 e que deve ser adotado até 2015.

Outra meta era a conclusão do Plano de Ação de Bali (COP-13, em 2007). Ela definiu ações referentes à mitigação, adaptação, financiamento, tecnologia e criação de capacidades para enfrentar as mudanças climáticas para países em desenvolvimento.

Delinear um plano de evolução de tecnologia e financiamento em longo prazo para os países em desenvolvimento foi mais um dos objetivos da reunião em Doha. Tal assunto retomou as discussões do estabelecimento do Fundo Verde para o Clima e o plano de trabalho da recém-estabelecida Comissão Permanente de Financiamento, bem como decisões formais sobre adoção e modo de operação do Centro e Rede de Tecnologia do Clima, do Mecanismo Tecnológico.

Havia também outras questões importantes a serem discutidas durante a COP-18, como um planejamento para aumentar a capacidade de adaptação dos países mais vulneráveis, sobretudo no que tange à proteção ante perdas e danos causados por processos graduais; a assistência para ação de países em desenvolvimento; ações referentes ao desmatamento; a captura e armazenamento de carbono; a questão da agricultura; a facilitação do desenvolvimento e transferência 
de tecnologia; além de ações para evitar consequências negativas da ação ante mudanças climáticas, ou seja, uma reflexão sobre possíveis consequências socioeconômicas decorrentes de iniciativas de mitigação ou adaptação.

Para tratar com uma pauta tão ampla, foram mobilizados os principais órgãos de negociação da UNFCCC, sintetizados no Quadro 1.

Quadro 1 - Principais órgãos de negociação da UNFCCC durante a COP-18 e finalidade

\begin{tabular}{|c|c|c|}
\hline \multicolumn{2}{|c|}{$\begin{array}{c}\text { Órgãos de Negociação da } \\
\text { UNFCCC }\end{array}$} & \multirow{2}{*}{\begin{tabular}{|l|}
\multicolumn{1}{|c|}{ Finalidade } \\
Órgão decisório supremo da UNFCCC, no qual \\
todos os Estados/Partes da Convenção estão \\
representados. Nas COPs, eles analisam \\
a implementação das decisões e dos demais \\
instrumentos jurídicos adotados. Também \\
definem como será sua implementação.
\end{tabular}} \\
\hline COP & Conferência das Partes & \\
\hline CMP & $\begin{array}{c}\text { Conferência das Partes } \\
\text { na Qualidade de Reunião } \\
\text { das Partes do Protocolo } \\
\text { de Quioto }\end{array}$ & $\begin{array}{l}\text { A CMP serve como Reunião das Partes } \\
\text { do Protocolo de Quioto. Todos os Estados que são } \\
\text { Partes do Protocolo de Quioto estão representados } \\
\text { na CMP, enquanto Estados que não são Partes } \\
\text { participam como observadores. A CMP revisa } \\
\text { a implementação do Protocolo de Quioto e toma } \\
\text { decisões para promover sua implementação. }\end{array}$ \\
\hline AWG-KP & $\begin{array}{c}\text { Grupo de Trabalho Ad } \\
\text { Hoc sobre Compromissos } \\
\text { Adicionais para Partes } \\
\text { Anexo I do Protocolo de } \\
\text { Quioto } \\
\end{array}$ & $\begin{array}{l}\text { Órgão Subsidiário criado durante a CMP } 1 \text { para } \\
\text { considerar futuros compromissos para as Partes } \\
\text { do Anexo I sob o Protocolo de Quioto. }\end{array}$ \\
\hline $\begin{array}{l}\text { AWG - } \\
\text { LCA }\end{array}$ & $\begin{array}{l}\text { Grupo de Trabalho } \\
\text { Ad Hoc sobre Ação } \\
\text { Cooperativa de Longo } \\
\text { Prazo no Âmbito da } \\
\text { Convenção }\end{array}$ & $\begin{array}{l}\text { Estabelecido como um Órgão Subsidiário durante } \\
\text { a COP-13 (Bali, 2007) com vistas a conduzir } \\
\text { a implementação plena, efetiva e sustentada } \\
\text { da Convenção por uma ação cooperativa de longo } \\
\text { prazo. Seu trabalho deveria ter sido completado } \\
\text { durante a COP-15 (Copenhagen, 2009), mas foi } \\
\text { prorrogado por três vezes desde esta data. }\end{array}$ \\
\hline ADP & $\begin{array}{c}\text { Grupo de Trabalho Ad } \\
\text { Hoc sobre a Plataforma } \\
\text { de Durban para Ação } \\
\text { Avançada }\end{array}$ & $\begin{array}{l}\text { Órgão Subsidiário estabelecido durante a COP-17 } \\
\text { (Durban, 2011) para desenvolver um protocolo, } \\
\text { outro instrumento legal ou um resultado acordado } \\
\text { com força legal no âmbito da Convenção e aplicável } \\
\text { a todas as Partes. Deve completar seu trabalho } \\
\text { o mais cedo possível, o mais tardar em } 2015 \text {, a fim } \\
\text { de adotar o mesmo na COP-20 para que possa } \\
\text { entrar em vigor e ser implementado em } 2020 \text {. }\end{array}$ \\
\hline SBSTA & $\begin{array}{l}\text { Órgão Subsidiário } \\
\text { de Assessoramento } \\
\text { Científico e Tecnológico }\end{array}$ & $\begin{array}{l}\text { Apoia o trabalho da COP e CMP por meio da } \\
\text { prestação de informaç̃̃es e opiniões atualizadas } \\
\text { sobre assuntos científicos e tecnológicos } \\
\text { relacionados à Convenção e ao Protocolo de Quioto. }\end{array}$ \\
\hline SBI & $\begin{array}{l}\text { Órgão Subsidiário de } \\
\text { Implementação }\end{array}$ & $\begin{array}{l}\text { Apoia o trabalho da COP e da CMP, por meio } \\
\text { da avaliação e revisão da implementação efetiva } \\
\text { da Convenção e do Protocolo de Quioto. }\end{array}$ \\
\hline
\end{tabular}

Fonte: ONU (2013); organizado pelos autores. 


\section{Discussões}

As discussões dos objetivos-chave e outros decorrentes desses foram realizadas em reuniões gerais e em encontros restritos promovidos pelos órgãos citados no Quadro 1. Elas ocorreram no Qatar National Convention Centre. Desde o começo mostraram-se lentas e difíceis, e assim seguiram até mesmo quando se iniciou o trabalho do setor de alto nível (que envolve ministros e/ou seus representantes) na segunda semana de trabalhos.

Mostrava-se urgente determinar os caminhos e regras da ordem ambiental internacional das mudanças climáticas. Assim, muitas esperanças foram depositadas no sucesso da Conferência. Os governos foram chamados pela secretária executiva da UNFCCC, Christiana Figueres, e pelo presidente da COP-18, S. E. Abdullah Bin Hamad Al-Attiyad - presidente da Autoridade de Controle Administrativo e Transparência do Qatar -, a concentrarem-se para o avanço na oferta de respostas internacionais às questões que envolvem as mudanças climáticas.

Logo no primeiro dia, Christiana Figueres ressaltou o perigo referente a um aquecimento do sistema climático mundial superior a $2{ }^{\circ} \mathrm{C}$. Citou dados do relatório Turn Down the Heat, elaborado pelo Postdam Institute for Climate Impact Research and Climate Analytics, encomendado pelo Banco Mundial (The World Bank, 2012). Esse documento apresenta cenários para o mundo caso ocorra uma elevação da temperatura mundial superior a $4{ }^{\circ} \mathrm{C}$. De acordo com esse informe, nessa situação haveria uma grande incerteza e criação de novos riscos que reduziriam a capacidade das sociedades antecipar e planejar as necessidades de adaptação futura. Figueres também comentou dados apresentados pela Organização Meteorológica Mundial, que apontam um novo recorde de aumento na concentração atmosférica de gases de efeito estufa para o ano 2011, referentes a quantidades de $\mathrm{CO}_{2}$ superiores a 390.9 partes por milhão - $140 \%$ em relação ao nível pré-industrial de 280 ppm (WMO, 2013). Note-se que em maio de 2013 foi ultrapassada a marca de 400 partes por milhão, que, de acordo com o IPCC (2007), vai levar a um aquecimento da ordem de 2,4 graus Celsius, em média, o que agravaria eventos como o descongelamento de glaciares e a acidificação dos oceanos.

O discurso do Secretariado da UNFCCC apontou a necessidade de desenvolver cenários mais precisos em escala geográfica detalhada sobre as consequências das mudanças climáticas. Também reafirmou a defesa do Princípio da Precaução, ${ }^{2}$ certamente numa tentativa de sensibilização dos tomadores de decisão presentes no evento.

Christiana Figueres afirmou que, ainda que tecnologia, financiamento e políticas para manter-se abaixo do objetivo fixado de $2{ }^{\circ} \mathrm{C}^{3}$ já estejam disponíveis para os governos, as ações, ainda que tenham crescido muito nos últimos três anos, seguem insuficientes. Tanto ela como o presidente da COP-18 ressaltaram a importância do aumento dos esforços para o preparo dos textos das decisões antes das sessões de alto nível, a fim de que os ministros tivessem em mãos um conjunto limitado de opções para chegarem a um acordo satisfatório, de forma 
a respeitar os prazos. Ambos pediram a rápida implementação das decisões já acordadas.

Ao longo dos dias surgiram muitos impasses que dificultaram enormemente a chegada a uma decisão consensual. A obtenção de uma base textual comum parecia ser algo inalcançável. As decisões foram postergadas até horas após o término oficial previsto para o evento, como costuma ocorrer nas rodadas da ordem ambiental das mudanças climáticas. Algumas partes chegaram a lamentar um retrocesso no tocante às decisões da COP-17, e mesmo à de Bali (COP-13, 2007). Observou-se que, apesar de apostarem no multilateralismo, na governança ambiental mundial, em geral os Estados buscam desenvolver estratégias que salvaguardem o interesse nacional, a despeito da urgência de ações.

Entre os temas mais polêmicos, destacaram-se o financiamento das ações de mitigação e de adaptação; a transferência de tecnologia aos países menos desenvolvidos; e a construção de capacidades em países em desenvolvimento, tanto para a mitigação como no tocante à redução dos efeitos das mudanças socioambientais que são e/ou serão sentidas por boa parte dos países, de acordo com o IPCC (2007). Desses temas centrais decorreram diversos outros, como questões referentes aos mecanismos de mercado previstos no Protocolo de Quioto, dentre eles o Mecanismo de Desenvolvimento Limpo e o Comércio de Emissões.

Verifica-se que, ainda que as mudanças climáticas exijam ações de cooperação que refletem a interdependência entre os países, a maior parte deles articula-se em grupos que refletem seus objetivos nacionais específicos. A mobilização em grupos dos países-membros na ordem ambiental sobre o clima, entendida como “... aquela que é elaborada para restringir a ação humana no ambiente, seja ele natural ou não, a nível mundial” (Ribeiro, 2001, p.16) está profundamente associada às relações de poder verificadas no sistema internacional contemporâneo, caracterizado por uma combinação de continuidades e de mudanças (Ribeiro; Sant'Anna, 2012). Nele estão países que tradicionalmente ocupam postos de comando, mas também assiste-se à emersão de novos países que, mesmo que sem o peso específico dos anteriores, começam a influenciar a tomada de decisões. Por isso observa-se que ao mesmo tempo que se estabelece um caminho cada vez maior para a cooperação entre os Estados, também são observadas forças de resistência, que confirmam as teorias realistas das relações internacionais e da geografia política (Ribeiro, 2010).

Giddens (2010), ao avaliar a geopolítica das mudanças climáticas, também aponta estes dois movimentos do sistema internacional: centrípeto e centrífugo. Para ele, ainda que as reações às mudanças globais do clima, à primeira vista, apontem para a colaboração internacional, os processos e interesses envolvidos que promovem a divisão são de grande peso. Marcovitch (2012, p.14), por sua vez, aponta que as negociações internacionais sobre mudanças climáticas "valoriza o possível em vez do necessário. Um possível ainda mais acanhado em con- 
sequência da crise financeira que assola as economias dos países desenvolvidos", ou seja, a conjuntura da crise internacional não pode ser negligenciada.

Em um contexto que exige cooperação, mas em que se pratica o velho paradigma do interesse nacional, combinado a uma grave crise financeira e econômica envolvendo países centrais do sistema internacional, não é fácil avançar. A mobilização dos países, em seus diversos grupos de pressão (Quadro 2), reflete a complexidade da questão.

Ressalta-se que, além desses, existem outros agrupamentos, haja vista que os países podem se articular em caráter não formal, segundo questões específicas e momentâneas; e integrar grupos diferentes à medida que o apoio a um determinado país ou grupo reflete seus interesses nacionais. Verifica-se a existência de grupos bastante heterogêneos, como o G77+China, que, em tese, procura promover o diálogo entre mais de cem países em desenvolvimento no sentido de defender seus interesses comuns ante os países desenvolvidos mas que engloba tanto países do BASIC como também de outros grupos bastante distintos, como OPEP e Países Menos Desenvolvidos.

De todo modo, ainda que tenha havido uma diversidade de agrupamentos durante a Conferência, verificou-se que a tensão e a maioria dos impasses refletiam significativa separação e diferenças entre países desenvolvidos e em desenvolvimento. Os países em desenvolvimento - alguns de forma bastante contundente, como Bolívia e Venezuela - defenderam a transferência de tecnologias e recursos financeiros por parte dos países desenvolvidos. Em sua maioria, criticaram países que não se comprometeriam em aderir aos mecanismos de mercado no segundo período de compromisso do Protocolo de Quioto, possibilidade que foi levantada em Doha.

Os países desenvolvidos, por sua vez, ressaltaram as medidas tomadas em seus territórios ante a questão, e defenderam maiores compromissos por parte das nações em desenvolvimento, especialmente o BASIC (Brasil, Índia, África do Sul, China) que, apesar de apresentarem grande crescimento econômico e serem atualmente responsáveis por boa parte das emissões de gases de efeito estufa, ancoram-se no G77+China. Os países desenvolvidos negaram, direta ou implicitamente, em sua maioria, o "Princípio das Responsabilidades Comuns, Porém Diferenciadas", ${ }^{4}$ que é central para a Convenção. Contudo, eles não apresentavam posicionamentos homogêneos. Como exemplo pode-se citar a posição proativa da União Europeia pela redução de emissões de gases estufa perante os Estados Unidos, que não assumiu reduções de emissões mais uma vez.

Era evidente a tensão presente nas negociações multilaterais, que evidenciaram profundamente as relações dissimétricas de poder (Raffestin, 1993), ainda que se realizassem esforços no sentido de escamotear os conflitos. As grandes diferenças entre os países indicam uma maior ou menor capacidade de pressão (Morgenthau, 2003), como a quantidade de membros das delegações. Ou seja, o poder se expressa também na capacidade de gerar argumentos que prevalecem nas discussões. 


\begin{tabular}{|c|c|}
\hline Grupo & Países Integrantes \\
\hline G77+ China & $\begin{array}{l}\text { Criado em } 1964 \text { por } 77 \text { países em desenvolvimento signatários da "Declaração } \\
\text { Conjunta dos Setenta e Sete Países" emitida na } 1^{a} \text { sessão da Conferência } \\
\text { das Nações Unidas sobre Comércio e Desenvolvimento (Unctad), hoje conta } \\
\text { com } 132 \text { países. É a maior organização intergovernamental de países em } \\
\text { desenvolvimento no âmbito da ONU. Busca fornecer meios para países do } \\
\text { "Sul" articularem e promoverem seus interesses coletivos e aumentarem } \\
\text { sua capacidade de negociação conjunta sobre todas as grandes questões } \\
\text { econômicas (à princípio) internacionais, de modo a promover a cooperação } \\
\text { Sul-Sul para o desenvolvimento. Grupo altamente heterogêneo. } \\
\text { Membros: Afeganistão, Argélia, Angola, Antígua e Barbuda, Argentina, } \\
\text { Bahamas, Bahrein, Bangladesh, Barbados, Belize, Benin, Butão, Bolívia, } \\
\text { Bósnia Herzegóvina, Botsuana, Brasil, Brunei, Burkina Faso, Burundi, } \\
\text { Camboja, Camarões, Cabo Verde, República Centro Africana, Chade, } \\
\text { Chile, China, Colômbia, Comoros, Congo, Costa Rica, Costa do Marfim, } \\
\text { Cuba, República Democrática da Coreia, República Democrática do Congo, } \\
\text { Djibuti, Dominica, República Dominicana, Equador, Egito, El Salvador, Guiné } \\
\text { Equatorial, Eritreia, Etiópia, Fiji, Gabão, Gana, Gâmbia, Granada, Guatemala, } \\
\text { Guiné, Guiné-Bissau, Guiana, Haiti, Honduras, Índia, Indonésia, Irã, Iraque, } \\
\text { Jamaica, Jordânia, Quênia, Kuwait, Laos, Líbano, Lesoto, Libéria, Líbia, } \\
\text { Madagascar, Malaui, Malásia, Maldivas, Mali, Ilhas Marshall, Mauritânia, nas } \\
\text { Maurício, Micronésia, Mongólia, Marrocos, Moçambique, Mianmar, Namíbia, } \\
\text { Nauru, Nepal, Nicarágua, Níger, Nigéria, Omã, Paquistão, Palestina, Panamá, } \\
\text { Papua Nova Guiné, Paraguai, Peru, Filipinas, Qatar, Ruanda, Santa Kitts e } \\
\text { Neves, Santa Lucia, São Vicente e Granadinas, Samoa, São Tomé e Príncipe, } \\
\text { Arábia Saudita, Senegal, Ilhas Seychelles, Serra Leoa, Cingapura, Ilhas } \\
\text { Salomão, Somália, África do Sul, Sri Lanka, Sudão, Suriname, Suazilândia, } \\
\text { Síria, Tadjiquistão, Tailândia, Timor Leste, Togo, Tonga, Trinidad e Tobago, } \\
\text { Tunísia, Turcomenistão, Uganda, Emirados Árabes Unidos, Tanzânia, } \\
\text { Uruguai, Vanuatu, Venezuela, Vietnã, lêmen, Zâmbia, Zimbábue. }\end{array}$ \\
\hline AOSIS & $\begin{array}{l}\text { A Aliança de Pequenos Estados Insulares é uma coalizão de países } \\
\text { compostos por ilhas pequenas e países costeiros de baixa altitude que } \\
\text { compartilham desafios de desenvolvimento semelhante e preocupações } \\
\text { referentes às suas vulnerabilidades no tocante aos efeitos adversos da } \\
\text { mudança climática global, como a elevação do nível do mar. É porta-voz } \\
\text { destes Estados dentro do sistema ONU. Possui atualmente } 44 \text { Estados e } \\
\text { observadores, de todos os oceanos e regiões do mundo. } \\
\text { Membros: Antigua e Barbuda, Bahamas, Barbados, Belize, Comoros, Cabo } \\
\text { Verde, Ilhas Cook, Cuba, Dominica, República Dominicana, Fiji, Estados } \\
\text { Federativos da Micronésia, Granada, Guiné-Bissau, Guiana, Haiti, Jamaica, } \\
\text { Kiribati, Maldivas, Ilhas Marshall, Ilhas Maurício, Nauru, Niue, Palau, Papua } \\
\text { Nova Guiné, Samoa, Singapura, Seychelles, São Tomé e Príncipe, Ilhas } \\
\text { Salomão, Santa Kitts e Nevis, Santa Lucia, São Vicente e Granadinas, } \\
\text { Suriname, Timor Leste, Tonga, Trinidad e Tobago, Tuvalu, Vanuatu. } \\
\text { Observadores: Samoa Americana, Antilhas Holandesas, Guam, Ilhas Virgens } \\
\text { (EUA), Porto Rico. }\end{array}$ \\
\hline $\begin{array}{c}\text { Grupo } \\
\text { Africano }\end{array}$ & $\begin{array}{l}\text { O Grupo Africano é o maior grupo regional por número de Estados Membros } \\
\text { da ONU, e o único grupo regional cujo território coincide com o continente do } \\
\text { qual seu nome se origina. É composto por } 54 \text { países que, nas negociações } \\
\text { sobre mudanças globais do clima, unem-se por interesses comuns. } \\
\text { Membros: Argélia, Angola, Benin, Botsuana, Burkina Faso, Burundi, } \\
\text { Camarões, Cabo Verde, República Centro Africana, Chade, Comoros, } \\
\text { Congo, Costa do Marfim, República Democrática do Congo, Djibuti, Egito, } \\
\text { Guiné Equatorial, Eritreia, Etiópia, Gabão, Gâmbia, Gana, Guiné, Guiné } \\
\text { Bissau, Quênia, Lesoto, Libéria, Líbia, Madagascar, Malaui, Mali, Mauritânia, } \\
\text { Maurício, Marrocos, Moçambique, Namíbia, Níger, Nigéria, Ruanda, São } \\
\text { Tomé e Príncipe, Senegal, Seychelles, Serra Leoa, Somália, África do } \\
\text { Sul, Sudão do Sul, Sudão, Suazilândia, Togo, Tunísia, Uganda, Tanzânia, } \\
\text { Zâmbia, Zimbábue. }\end{array}$ \\
\hline
\end{tabular}

Fonte: Elaborado pelos autores. 
Além disso, Michaelowa e Michaelowa (2012) também chamam a atenção para outros fatores que influenciam as rodadas de negociações sobre as mudanças no sistema climático em escala geográfica global, como ocorreu na COP-18, como as características específicas das diferentes delegações e suas estratégias; além das habilidades de negociação e movimentos táticos da presidência da conferência. Esses autores também destacam como as estratégicas interagem com as características exógenas dos países, incluindo seus poderes em termos de recursos naturais e econômicos e seu nível de vulnerabilidade, dentre outros fatores que, ainda que para eles se mostrem menos importante do que o esperado, podem ser significativos, como o tamanho da delegação e a experiência de sua liderança. Eles analisam não somente a probabilidade geral de alcançar um acordo, mas também as vantagens e desvantagens de certas escolhas estratégicas para as delegações individuais e o sucesso das mesmas no processo de negociação internacional. ${ }^{5}$

\section{Resultados}

Na COP-18 os países criaram uma emenda ao Protocolo de Quioto que estabeleceu seu segundo período de compromisso, com duração de oito anos. Decidiu-se que seriam preservados seus requisitos legais e regras de contabilidade. Entretanto, 37 países (Quadro 3) assumiram novas metas de redução e terão até 2014 para comprovar suas reduções de emissões com vistas a aumentar seus níveis de ambição. ${ }^{6}$ Tais metas no total significam uma redução de $18 \%$ das emissões dos países desenvolvidos em relação ao ano base de 1990. Rússia, Nova Zelândia, Canadá e Japão decidiram não participar da segunda fase do Protocolo, o que acabou por enfraquecê-lo. Os Estados Unidos também mantiveram sua posição e não integram o acordo.

Quadro 3 - Países Anexo B do Protocolo de Quioto ante o $2^{\circ}$ Período de Compromisso

\begin{tabular}{c|l}
\hline \multicolumn{2}{c}{ Países Anexo B - Protocolo de Quioto - $2^{\circ}$ Período de Compromisso } \\
\hline \multirow{3}{*}{ Aderiram } & $\begin{array}{l}\text { Austrália, Áustria, Belarus, Bélgica, Bulgária, Croácia, Chipre, República } \\
\text { Tcheca, Dinamarca, Estônia, Finlândia, França, Alemanha, Grécia, Hungria, } \\
\text { Irlanda, Islândia, Itália, Kazaquistão, Letônia, Liechtenstein, Lituânia, } \\
\text { Luxemburgo, Malta, Mônaco, Holanda, Noruega, Polônia, Portugal, Romênia, } \\
\text { Eslováquia, Eslovênia, Espanha, Suécia, Suíça, Ucrânia e Reino Unido. }\end{array}$ \\
\hline Não Aderiram & Canadá, Japão, Nova Zelândia e Federação Russa. \\
\hline
\end{tabular}

Fonte: Elaborado pelos autores.

Foi definido um calendário para que os países cheguem a um acordo mundial sobre o tema em 2015 e aumentem o nível de ambição antes de 2020, quando esse entrará em vigor. A intenção é garantir que o aumento de temperatura de fato restrinja-se a até $2{ }^{\circ} \mathrm{C}$, conforme já acordado pelas partes durante a COP-15 (2009).

Em relação a novas infraestruturas no tocante a tecnologia e financiamento, os governos selecionaram a República da Coreia como sede do Fundo Verde 
para o Clima e referendaram o plano de trabalho do Comitê Permanente de Financiamento. Prevê-se que o funcionamento do Fundo comece na segunda metade de 2013, na cidade de Sondgo; de forma a permitir o desenvolvimento ampliado de atividades em 2014. Também foi definido um consórcio dirigido pelo PNUMA como instituição anfitriã do Centro de Tecnologia do Clima (CTC) durante um período inicial de cinco anos. O CTC é o órgão encarregado do funcionamento do Mecanismo Tecnológico da UNFCCC, juntamente com sua rede associada.

Quanto ao financiamento em longo prazo, os países desenvolvidos se comprometeram formalmente a auxiliar os países em desenvolvimento e pretendem mobilizar cerca de US\$ 100 milhões para adaptação e mitigação até 2020. $\mathrm{O}$ acordo final também aponta que esse aporte financeiro não deve ser interrompido enquanto são realizados outros esforços. A Alemanha, a União Europeia, a Dinamarca, o Reino Unido e a Suécia anunciaram financiamentos para até 2015.

Além desses, podem ser destacados outros resultados obtidos durante a COP-18. Os governos acordaram um processo criterioso no tocante à ciência da mudança do clima, que começará em 2013 e deve terminar em 2015, com vistas a apresentar a real situação das ameaças, bem como apontar necessidades específicas para ação.

No tocante à adaptação, os governos discutiram sobre formas de fortalecimento de capacidades das partes mais vulneráveis por meio de planejamento. Foi definido um caminho para disposições institucionais concretas ante perdas e danos causados por fenômenos graduais, como o aumento do nível do mar, bem como normas para colocar em prática planos nacionais de adaptação para países menos desenvolvidos, que contariam com financiamentos e outros tipos de apoio.

Os governos completaram um registro para consignar medidas de mitigação dos países em desenvolvimento que buscam reconhecimento ou apoio financeiro, que será realizado por meio de uma plataforma web flexível. Também acordaram ampliar a capacitação de técnicos de países pobres e em desenvolvimento por meio da educação e formação em matérias relacionadas às mudanças do clima, de forma a ampliar o conhecimento e o apoio ao novo regime pós-2020.

Os mecanismos de mercado - Mecanismo de Desenvolvimento Limpo, Implementação Conjunta e Comércio de Emissões - tiveram continuidade assegurada, de forma que seu acesso será ininterrupto para os países desenvolvidos que aceitaram metas para essa nova fase. Contudo, houve discordância em relação à transferência de unidades de créditos de emissões do primeiro para o segundo períodos. Por isso países como Austrália, Japão, Liechtenstein, Mônaco, Noruega, Suíça e União Europeia deixaram claro que não comprarão unidades excedentes referentes a esse processo.

Foi definido um programa de trabalho para continuar a elaboração de um novo mecanismo de mercado e outro para criação de um marco para reco- 
nhecer mecanismos estabelecidos fora da UNFCCC, como programas nacionais ou bilaterais, de forma a considerar seu valor para o cumprimento de metas. Os governos também sinalizaram intenções para redução do desmatamento; para o estudo de novas formas de assegurar eficácia de projetos de captura e armazenamento de carbono; para a reafirmação do compromisso no tocante à transferência de tecnologia e combate às consequências negativas das ações que visam reduzir emissões.

Dessa forma, foi definida a chamada Porta Climática de Doha, por meio da qual os governos devem passar rapidamente a impulsionar as soluções propostas. Segundo a secretária executiva da UNFCCC, após esse evento, a discussão deveria referir-se, sobretudo, à escala, rapidez, determinação e seguimento ao calendário.

Os trabalhos de Bali (2007) foram concluídos e assegurou-se que as questões pendentes desse acordo continuarão fazendo parte do processo da UNFCCC. A cidade de Varsóvia, na Polônia, foi definida como sede da COP19, a realizar-se em novembro de 2013.

De modo geral, ao analisar os resultados do evento, verifica-se que, apesar de manter o Protocolo de Quioto, que acabou legitimado mais uma vez, e a ONU como fórum das discussões sobre o tema, o acordo final ficou muito aquém do nível de ambição esperado para o encontro e ante os avanços da ciência da mudança do clima, que cada vez mais ressaltam a necessidade de medidas urgentes.

As negociações foram lentas e as decisões foram tomadas nos últimos momentos. Na verdade, em uma prorrogação, como costuma ocorrer em reuniões desse tipo. Diversos temas importantes não tiveram avanços significativos, como a questão dos recursos financeiros e tecnológicos, comentados anteriormente. Muito pontos discutidos ficaram ainda no plano geral, sem definição concreta de mecanismos que facilitem sua implementação nos territórios nacionais, como a questão do financiamento. Houve grandes críticas no tocante ao nível de ambição acordado, cujo aumento foi deixado para os próximos eventos. A crise econômica internacional foi bastante citada como obstáculo à tomada de medidas mais ambiciosas.

Parte dos países desenvolvidos concordou em assumir novas metas, mas houve uma perda em relação ao primeiro período do Protocolo de Quioto. Outros países aceitaram o novo acordo, como os países do grupo AOSIS, que teceram muitas críticas durante o encontro pois acreditam que sua situação não foi claramente debatida nem que foi dada atenção aos problemas relacionados ao oceano, como a maior acidificação das águas e a elevação do nível.

Além disso, verificou-se que houve uma menor presença de lideranças mundiais, mesmo nas reuniões de alto nível, o que aponta uma menor preocupação com as decisões referentes ao tema. Também foi percebida uma baixa cobertura da imprensa mundial do evento, o que reflete em baixa divulgação à 
sociedade em geral, com diferentes consequências, como diminuição do apoio e da pressão popular por medidas de mitigação/adaptação.

Diante desse cenário, entende-se que a definição desse acordo global, com metas para todos os países, será algo extremamente complexo e difícil.

\section{As posições brasileiras}

Para os representantes do Brasil, a questão central a ser resolvida na COP18 era a definição do segundo período de compromisso do Protocolo de Quioto, haja vista que o mesmo constitui a única agenda legal e instrumento com obrigações nacionais. Era preciso dar consistência legal aos trabalhos futuros da UNFCCC, bem como garantir a continuidade do mercado de carbono, sobretudo o Mecanismo de Desenvolvimento Limpo, de grande importância para os países em desenvolvimento.

Em discurso durante o evento, a ministra do Meio Ambiente, Izabella Teixeira, ressaltou o Brasil ter sediado a Conferência Rio+20, ocorrida em junho de 2012. Afirmou que, em paralelo aos processos lançados durante esse encontro, as negociações que envolvem a Plataforma de Durban podem impactar de maneira positiva políticas públicas para o desenvolvimento sustentável nos próximos anos.

Em resposta ao pessimismo acerca desse segundo período de compromisso, defendeu que mantê-lo era a garantia de toda a lógica das negociações que de algum modo permitiram a manutenção das metas previstas pela Convenção. Ainda que os avanços em termos de mitigação de emissões tenham sido, até o momento, absolutamente insuficientes, o governo brasileiro entende que, sob outros aspectos a UNFCCC progrediu muito, por exemplo, em relação ao conhecimento acerca da ciência da mudança do clima, bem como das circunstâncias nacionais em termos de ação ante o problema. Para a ministra, sem essas referências, os países desenvolvidos tenderiam a fazer ainda menos para mitigar o aquecimento global.

Outro assunto essencial era o encerramento das discussões do AWG-LCA, que basicamente aborda regras e provisões no âmbito da Convenção, de forma a fechar o processo iniciado em Bali. Era preciso encontrar uma solução para cada uma de suas questões, para que pudesse ser concluída de maneira adequada, ainda que as questões pendentes fossem remanejadas para outro grupo de negociações. Para o Brasil, diversos elementos da LCA não seriam completados por recusa dos países desenvolvidos, como a discussão sobre os direitos de propriedade intelectual. Justamente pela LCA abordar temas diversos, como mitigação e adaptação, as negociações foram bastante delicadas e sua chave estaria na questão do apoio financeiro, o que resultou em muita polêmica.

A COP-18 era vista, pelo governo brasileiro, como o encerramento de uma fase para o combate às mudanças climáticas. Esse evento teria por objetivo fechar as questões que permitiriam que a UNFCCC continuasse trabalhando nos anos seguintes e, em paralelo, começar as discussões referentes à Plataforma de 
Durban, que devem gerar um novo instrumento juridicamente vinculativo a ser definido até 2015, para entrar em vigor em 2020.

Segundo os chefes da delegação brasileira, a COP-19 será uma oportunidade para a exploração de novas possibilidades, de forma que em Doha era preciso manter a discussão aberta, para ter tempo para considerar diversas propostas, de diferentes partes, de forma a encontrar novas soluções, mais efetivas do que o atual modelo. Em outras palavras, era o momento de definição de uma nova estrutura para a Convenção e sua implementação, a entrar em vigor em 2020. Os mesmos também afirmaram a necessidade de envolver mais profundamente os países/grupos ao considerar a promessa de que os acordos conseguirão aumentar a ambição de forma que a temperatura não suba além de $2{ }^{\circ} \mathrm{C}$, conforme acordado em Copenhague. Para tal, era fundamental obter resultados significativos tanto no âmbito da AWG - KP como na AWG - LCA e na ADP.

Há diferenças entre as negociações de Doha e as ocorridas em Durban em 2011. Na COP-17, havia um clima de incerteza no tocante às realizações às quais os países poderiam chegar. Já em Doha havia objetivos definidos, como a definição do segundo período de compromisso, o fechamento da AWG - LCA e o planejamento do trabalho da ADP.

Segundo os ministros brasileiros nas negociações, o grande obstáculo para o sucesso do evento centrava-se na falta de confiança entre os países, haja vista que eles ficavam a esperar os demais tomarem a frente do processo. Esse jogo político atravancou as decisões. Outra dificuldade veio das diferentes expectativas dos países-membro. Ainda que os países estivessem basicamente divididos em Anexo I e Não Anexo I, havia uma série de outras subdivisões, grupos concentrados em assuntos específicos como o aumento da ambição, a questão da integridade ambiental, dentre outros. Além disso, havia países bastante insatisfeitos com o processo iniciado em Bali com a LCA e que queriam adentrar o mais breve possível na nova fase.

O Brasil atuou no BASIC, que é um subgrupo do G77 + China, bloco de países que compartilhavam preocupações semelhantes e que dialogaram continuamente com vistas à apresentação de uma posição conjunta. Para o BASIC, Doha deveria construir um acordo que não satisfizesse a todos, mas que pudesse ser aceito por todos. Ou seja, trabalhou-se por buscar um equilíbrio.

O Brasil, assim como os demais países do BASIC, não renegociou o Princípio das Responsabilidades Comuns, Porém Diferenciadas, assim como nenhum outro princípio da Convenção, que serão objeto de discussão da COP-19, quando o novo acordo será negociado. Segundo a ministra Izabella Teixeira, a nova fase irá fortalecer os princípios e provisões da UNFCCC, mas com maiores níveis de compromissos por todas as partes.

Em diversos momentos, a delegação brasileira ressaltou que, ainda que de acordo com os princípios da Convenção os países desenvolvidos devessem liderar o processo e se comprometer a reduzir significativamente suas emissões, 
o que se verifica é que os países em desenvolvimento vêm tomando a frente, sobretudo os do grupo BASIC. Eles oferecem metas voluntárias de redução, o que nem sempre é observado pelos governos.

Para o BASIC, os países que se industrializaram mais cedo devem reduzir as emissões antes que os demais, não tanto por suas emissões históricas, mas, sobretudo, porque detêm recursos financeiros e tecnológicos para tal. Esses países podem apresentar uma sociedade com menos desigualdades sociais e não precisam buscar soluções para enfrentar a pobreza, como ocorre com os países emergentes.

Segundo o representante brasileiro na negociação, André Correia do Lago, os países desenvolvidos estão desarticulados. Nesse grupo existem países Anexo I que não são parte do Protocolo, como Estados Unidos e Canadá; países que são parte do Protocolo de Quioto, mas não aderiram ao segundo período de compromisso, como Japão e Nova Zelândia; e países que participarão dessa segunda fase. A baixa adesão, segundo ele, compromete a integridade ambiental porque, ainda que sejam tomadas medidas fora do acordo por parte dos membros que não aderiram, essa atitude permitirá questionamentos sobre a solidez de suas metodologias para redução de emissões, o que pode ampliar o nível de incerteza das emissões reais.

Para o Brasil, ainda que todos estivessem concentrados em criticar a falta de ambição dos países que adentravam o segundo período de compromisso do Protocolo de Quioto, era preciso centrar as atenções nas razões que levaram os demais a não aderir, bem como sobre como atuarão a partir do término do primeiro período de compromisso. Isso porque, se países desenvolvidos, que possuem muito mais recursos financeiros e tecnológicos, não estão se comprometendo mesmo com ambições "modestas", eles não poderiam esperar que os países em desenvolvimento fossem muito ambiciosos, ainda que muitas vezes as discussões pareçam tomar essa direção. Ou seja, as discussões em Doha quase ficaram estagnadas pela baixa ambição de redução, que convinha a diferentes grupos de países-membro.

No tocante ao contexto brasileiro, a delegação ressaltou que o Brasil vem se destacando na mitigação de emissões de gases de efeito estufa de forma a cumprir eficazmente seus compromissos voluntários. Em diferentes momentos, destacou a redução das emissões no tocante ao uso do solo e florestas, que respondem por mais de $60 \%$ das emissões brasileiras de GEE. A taxa de desmatamento na Amazônia foi reduzida em 27\% em comparação com a do ano $2011 .^{7}$ Do mesmo modo a China apresentou uma política nacional de redução de emissões por meio de ações no campo da geração de energia por fontes renováveis. Esses exemplos foram citados para apontar que países em desenvolvimento estão liderando o processo de mitigação. Mas, é preciso insistir, como são metas voluntárias por meio de ações que estão fora dos documentos da UNFCCC, e portanto não sujeitas a fiscalização, existem dívidas sobre a real eficácia dessas ações. 
A ministra do meio ambiente, Izabella Teixeira, também destacou em seu discurso a criação da Política Nacional de Mudanças Climáticas, que prevê planos setoriais de mitigação e adaptação às mudanças do clima, como indústria, agricultura e energia, que estariam nos "estágios finais" do processo político de tomada de decisão. O objetivo é cortar emissões entre $36,1 \%$ e $38,9 \%$ até 2020, números informados à UNFCCC após a COP-15 (dezembro de 2009). A criação do Fundo de Mudança do Clima e do Fundo Amazônico, dedicados ao financiamento de atividades e projetos que contribuem de maneira efetiva à implementação de uma agenda de mitigação e de adaptação no Brasil, também foi citada pela representante brasileira. Contudo, afirmou também que o esforço brasileiro não elimina ou minimiza a necessidade da existência de uma fonte principal de financiamento para apoio das ações em países em desenvolvimento, a ser provido pelos países desenvolvidos.

Esse é um dos pontos de mais difícil solução nas negociações sobre mudanças climáticas. Reforçando a posição dos membros do BASIC, o governo brasileiro afirmou que o financiamento é um ponto fundamental, haja vista que países como Brasil, China, Índia e África do Sul, ainda que apresentem um crescimento econômico significativo, possuem um enorme déficit social a resolver, o que impediria investir recursos na mitigação e adaptação de países mais pobres. Desse modo, ficou sem esclarecimento como se dará o financiamento de curto prazo, negociado em Copenhague (30 bilhões de dólares em três anos), e o financiamento de longo prazo (até 2020) que visa chegar a 100 bilhões de dólares por ano. Esses recursos devem ser destinados principalmente para a adaptação de países mais pobres. Para o chefe da delegação brasileira, o embaixador Luiz Figueiredo, a COP-18 seria o momento de os países desenvolvidos honrarem seus compromissos e responsabilidades históricas e definirem o financiamento em termos quantitativos, em vez de os países em desenvolvimento aceitarem, COP após COP, o não aparecimento dos recursos na proporção necessária à implementação dos acordos e proporcional à gravidade e urgência da situação.

Durante a COP-18, o Brasil defendeu a continuidade do Mecanismo de Desenvolvimento Limpo. Destacou sua importância enquanto instrumento efetivo de redução de emissões de GEE, justamente por seus dois princípios básicos: a adicionalidade, que não o torna um jogo de soma zero - reduzir num lugar e intensificar em outro; e a demanda, gerada pelo Protocolo de Quioto no tocante aos países com metas a cumprir e que podem comprar certificados de redução de emissões. Contudo, segundo a chefia da delegação brasileira, a baixa ambição e a ausência de países no segundo período de compromisso fazem que a demanda diminua e o preço do carbono caia; o que deveria ser corrigido para garantir a manutenção dessa estrutura. Para o Brasil, o MDL não pode ser dissociado do Protocolo de Quioto por conta desses dois princípios; é um acordo top-down e se estivesse fora seria bottom-up. O que não significa que não possam ser criados outros mecanismos para 2020. Assim, o governo brasileiro dedicou-se bastante a essa discussão, haja vista que há, no Brasil, centenas de projetos de MDL. 
No tocante ao mecanismo REDD, o embaixador Figueiredo afirmou que o país introduziu esse item na agenda internacional e foi o primeiro a desenvolver proposta escrita sobre o tema. Ressaltou a esperança de ver resolvida essa questão, bem como negou a verificação internacional acerca de projetos desse tipo desenvolvidos no país, porque o que existe é um sistema de acesso aos resultados para confirmação da solidez metodológica e exatidão numérica. A fiscalização, portanto, deveria ser nacional.

Além de pronunciamentos que expressavam aspectos comuns aos membros do BASIC, a delegação brasileira conduziu momentos importantes da reunião. O embaixador brasileiro, Luiz Figueiredo, e o da Noruega, Bard Vegar Solhjell, dirigiram as negociações sobre o compartilhamento dos créditos do MDL, que é depositado no fundo de adaptação. Uma das intenções dos negociadores era estender uma parcela de recursos aos demais mecanismos, com o intuito de captar recursos para o financiamento do Fundo de Adaptação. Outro ponto debatido foi o uso do mecanismo flexível por países que não fariam parte do segundo período, sobretudo o MDL.

\section{Considerações finais}

Apesar do cenário pessimista, observou-se que a COP-18 conseguiu ao menos esboçar o segundo período de compromisso do Protocolo de Quioto. O baixo nível de ambição predominou, como se demonstrou neste artigo. Na verdade, tanto países desenvolvidos quanto emergentes necessitavam ganhar tempo para ajustar suas economias a novos padrões de emissões de gases estufa. Por isso as negociações foram truncadas e pouco avançaram.

Ao analisar a participação do Brasil na COP-18, verificou-se que o país, ainda que se alinhe com o grupo do G77 + China e, mais propriamente, com o BASIC, procurou desempenhar posição de liderança ao longo da reunião. Propôs mudanças no texto, incentivou o aumento de ambição dos países e destacou-se quando designado pelo presidente da COP-18 para auxiliar em negociações específicas no tocante aos mecanismos de mercado.

Em diversos momentos ressaltou estar tomando a frente do processo, assim como os demais países do BASIC, para cumprir compromissos voluntários de redução e gerar constrangimentos aos países desenvolvidos. Pouco antes, entretanto, assistia-se no país à aprovação do novo Código Florestal, que delineia uma maior devastação florestal...

O governo brasileiro mostrou-se bastante disposto a colaborar para a criação do novo acordo universal a ser definido na COP-19, que será em Varsóvia em novembro de 2013. Contudo, ainda é cedo para afirmar em que moldes ele será definido, bem como o grau de comprometimento do Brasil: se ainda permanecerá fortemente ancorado no G77 + China, o que é mais provável e confortável, ou se assumirá responsabilidades diferenciadas por ser um grande país em desenvolvimento, integrante do BASIC, ainda que apresente problemas sociais graves e necessite de financiamento, transferência de tecnologia e cons- 
trução de capacidades para enfrentar as necessárias medidas de adaptação com inclusão social.

Talvez essa encruzilhada espelhe a nova posição do Brasil no sistema internacional. Reconhecê-la é o primeiro passo para repensar a política externa, em especial em temas nos quais tem tradição, como os que envolvem a ordem ambiental internacional.

Notas

1 Unidade de medida do cumprimento dos compromissos vinculantes de redução de emissões.

2 Princípio usado no direito que defende a aplicação de medidas preventivas quando uma atividade se coloca como uma ameaça à saúde humana ou ao meio ambiente, ainda que suas causas e efeitos não tenham sido totalmente explicitados pela ciência (Derani, 2008).

3 Durante a COP-15, realizada em Copenhague, Dinamarca (2009), os países da UNFCCC decidiram intensificar esforços no sentido de garantir que a temperatura média do planeta não aumentasse mais de $2{ }^{\circ} \mathrm{C}$ : "Convenimos en que se requieren fuertes reducciones de las emisiones mundiales, a la luz de la ciencia y de la información recogida en el Cuarto Informe de Evaluación del IPCC, con miras a lograr una disminución de dichas emisiones que permita mantener el aumento de la temperatura mundial por debajo de $2{ }^{\circ} \mathrm{C}$, y nos proponemos tomar medidas para cumplir este objetivo de conformidad con la ciencia y sobre la base de la equidad" (ONU, 2009, p.6).

4 Note-se que esse princípio é um dos temas de maior discórdia na UNFCCC. Ele foi usado para que os países que emitiram gases estufa no passado reduzissem as emissões antes dos demais, o que garantiria um volume de emissões aos que se industrializaram depois. O argumento dos países ricos é que os emergentes emitem muito $\mathrm{CO}_{2}$ equivalente hoje em dia, superando muitos países industrializados. Por sua vez, os países emergentes advogam que suas emissões são baixas quando comparam o volume de emissões per capita entre países ricos e emergentes.

5 Viola, Franchini e Ribeiro (2013) e Veiga (2013) também reconhecem a centralidade das negociações da ordem internacional das mudanças climáticas no sistema internacional.

6 Nível de ambição é uma expressão usada na ordem ambiental das mudanças climáticas para apontar a quantidade de redução de emissões de gases estufa realizada pelo conjunto dos países-membros da UNFCCC. Ela será alta se as reduções forem elevadas e baixa se não corresponderem às necessidades apontadas pelos especialistas. Desde 2010 o PNUMA publica um relatório de emissões que aponta o déficit dos países em relação às metas acordadas de redução no qual explora o nível de ambição (UNEP, 2012).

7 Esse indicador é questionado por várias $\mathrm{ONG}$, como o Instituto Imazon, que afirma que a redução do desmatamento da Amazônia foi de 35\% em 2011. Disponível em: <http://www.imazon.org.br/publicacoes/outros/desmatamento-e-degradacao-florestal-do-bioma-amazonia-2000-2010>. Acesso em: maio de 2013. 
Referências

DERANI, C. Direito ambiental econômico. São Paulo: Saraiva, 2008.

GIDDENS, A. A política das mudanças climáticas. Rio de Janeiro: Zahar, 2010.

IPCC. Cambio climático 2007: Informe de síntesis. Contribución de los Grupos de trabajo I, II y III al Cuarto Informe de evaluación del Grupo Intergubernamental de Expertos sobre el Cambio Climático [Equipo de redacción principal: Pachauri, R.K. y Reisinger, A. (directores de la publicación)]. Genebra: IPCC, 2007.104p.

MARCOVITCH, J. A governança internacional do meio-ambiente. In: RIBEIRO, W. C. (Org.) Governança da ordem ambiental internacional e inclusão social. São Paulo: Annablume, 2012. p.13-27.

MICHAELOWA, K.; MICHAELOWA, A. Negotiating climate change. Climate Policy, v.5, n.12, p.527-33, 2012.

MORGENTHAU, H. J. A politica entre as nações. A luta pelo poder e pela paz. São Paulo: Ioesp-UnB-Ipri, 2003.

ONU. Convención marco sobre el cambio climático. Acuerdo de Copenhague. Copenhague: UNFCCC, 2009.

ONU. United Nations Framework Convention on Climate Change. Bodies. Disponível em: http://unfccc.int/bodies/items/6241.php. Acesso em: maio de 2013

RAFFESTIN, C. Por uma geografia politica do poder. Trad. Maria Cecília França. São Paulo: Ática, 1993.

RIBEIRO, W. C. A ordem ambiental internacional. São Paulo: Contexto, 2001.

Geografia política e gestão internacional dos recursos naturais. Estudos Avançados, São Paulo, v.24, n.68, 2010. Disponível em: <http://www.scielo.br/ scielo.php?script=sci_arttext\&pid=S0103-40142010000100008\&lng=pt\&nrm=iso $>$. <http://dx.doi.org/10.1590/S0103-40142010000100008>.

RIBEIRO, W. C.; SANT'ANNA, F. Governança da ordem ambiental internacional. In: RIBEIRO, W. C. (Org.) Governança da ordem ambiental internacional e inclusão social. São Paulo: Annablume, 2012. p.45-68.

THE WORLD BANK. International Bank for Reconstruction and Development. Turn down the heat. Why a $4^{\circ} \mathrm{C}$ Warmer World Must Be Avoided. Washington, DC: The World Bank, 2012.

UNEP. The Emissions Gap Report 2012. Nairobi: United Nations Environment Programme (UNEP), 2012.

VEIGA, J. E. da. A desgovernança mundial da sustentabilidade. São Paulo: Editora 34, 2013.

VIOLA, E.; FRANCHINI, M.; RIBEIRO, T. L. Sistema internacional de hegemonia conservadora: governança global e democracia na era da crise climática. São Paulo: Annablume, 2013.

WMO. A. Summary of current climate change findings and figures. Genebra: WMO, 2013. 
RESUMO - Este artigo apresenta um relato sobre a Décima Oitava Conferência das Partes da Convenção-Quadro das Nações Unidas sobre Mudança do Clima (COP-18), realizada entre os dias 26 de novembro e 7 de dezembro de 2012, em Doha, no Emirado do Qatar. Além disso, analisa as posições brasileiras no encontro. Para tal, baseia-se em informações obtidas no evento para analisar as posições brasileiras nas negociações da ordem ambiental internacional das mudanças climáticas. $\mathrm{O}$ artigo conclui que o Brasil está em uma encruzilhada: permanecer junto ao grupo G77 + China ou liderar as negociações, com os ônus que ela apresenta, diante de sua posição no sistema internacional. PALAVRAS-CHAVE: Ordem ambiental internacional, Mudanças climáticas, COP-18, Brasil. ABSTRACT - This article presents an narrative of the Eighteenth Conference of the Parties to the UN Framework Convention on Climate Change (COP-18), which occurred in Doha (Emirate of Qatar) from November 26 to December 7. Moreover, analyzes the Brazilian position at the meeting. To this end, based on information collected at the event, analyzes the Brazilian positions in the negotiations of international environmental order of climate change. The article concludes that Brazil is at a crossroads: stay with the G77 + China group or lead the negotiations with the burdens she has in front of its position in the international system.

KEYWORDS: Order international environmental, Climate change, COP-18, Brazil.

Carolina Gamba é aluna de doutorado do Programa de Pós-Graduação em Geografia Humana da USP. Bolsista da Capes e membro da delegação brasileira na COP-18, com apoio da Pró-Reitoria de Pós-Graduação da USP. @ - carolina.gamba@ig.com.br

Wagner Costa Ribeiro é professor titular do Departamento de Geografia, membro do Grupo de Pesquisa Meio Ambiente e Sociedade do IEA e pesquisador do CNPq. @ - wribeiro@usp.br

Recebido em 20.5.2013 e aceito em 13.6.2013. 